ISSN 0103-9954

\title{
MÉTODOS DE CONTROLE DE Prosopis juliflora (Sw.) DC. (FABACEAE) EM ÁREAS INVADIDAS NO SEMIÁRIDO DO BRASIL ${ }^{1}$
}

\author{
CONTROL METHODS OF Prosopis juliflora (Sw.) DC. (FABACEAE) IN INVADED AREAS IN THE \\ SEMIARID REGION OF BRAZIL
}

\author{
Gerlândio Suassuna Gonçalves ${ }^{2}$ Leonaldo Alves de Andrade ${ }^{3}$ Klerton Rodrigues Forte Xavier ${ }^{4}$ \\ José Ferreira da Silva ${ }^{5}$
}

\begin{abstract}
RESUMO
O objetivo deste estudo foi avaliar a eficiência de diferentes métodos no controle de Prosopis juliflora, espécie exótica invasora na região semiárida do Nordeste do Brasil. O delineamento utilizado foi inteiramente casualizado, em esquema fatorial triplo 2x2x8 (duas populações da espécie; dois estádios de crescimento - regenerante e adulto; e oito tratamentos de controle), com 10 repetições. Os tratamentos testados foram: testemunha; anelamento do caule; anelamento e pincelamento do caule com óleo lubrificante usado; anelamento do caule e aplicação de 2,4-D + picloram; corte raso; corte raso seguido de queima das cepas; corte raso e pincelamento de óleo lubrificante usado nas cepas; e corte raso e aplicação de 2,4-D + picloram nas cepas. No total foram monitorados 320 indivíduos, dentre estes, 160 regenerantes e 160 adultos. As variáveis avaliadas foram: porcentagem de controle; número de brotações; diâmetro e comprimento de brotações. Dentre os tratamentos avaliados, os que se mostraram mais eficientes no controle de Prosopis juliflora foram o corte raso, seguido de queima das cepas e aplicação de 2,4-D + picloram em plantas cortadas e aneladas. O pincelamento de óleo lubrificante na base de plantas aneladas também se mostrou uma estratégia promissora no controle da invasora.
\end{abstract}

Palavras-chave: invasão biológica; controle de plantas invasoras; algaroba; caatinga.

\section{ABSTRACT}

The objective of this study was to evaluate the efficiency of different methods to control Prosopis juliflora, invasive alien species in the semiarid region of northeastern Brazil. The experimental design was completely randomized in triple factorial scheme $2 \times 2 \times 8$ (two populations of the species, two growth stages - regenerating and adult individuals and eight control treatments), with 10 repetitions. The treatments were: control, girdling of the stem, girdling and brushing of used lubricating oil; girdling and application of 2,4-D + picloram, clear cutting, clear cutting followed by burning of the stump; clear cutting and brushing of used lubricating oil; and clear cutting and application of 2,4-D + picloram. In total 320 individuals were monitored, among these, 160 regenerates and 160 adults individuals. The variables evaluated were: percentage of control, number of shoots, diameter and length of shoots. According to the results among the treatments, those who were more effective in controlling Prosopis juliflora were clear cutting followed by

1 Parte da Dissertação de mestrado do primeiro autor, apresentada ao Programa de Pós-Graduação em Agronomia da Universidade Federal da Paraíba, Brasil.

2 Engenheiro Agrônomo, Doutorando em Agronomia Tropical, Universidade Federal do Amazonas, Av. General Rodrigo Octávio Jordão Ramos, 3000, Setor Sul, Coroado I, CEP 69077-000, Manaus (AM), Brasil. gsuassunag@hotmail.com

3 Engenheiro Agrônomo, Dr., Professor do Departamento de Fitotecnia, Centro de Ciências Agrárias, Universidade Federal da Paraíba, CEP 58397-000, Areia (PB), Brasil. laa leon@hotmail.com

4 Biólogo, Doutorando em Agronomia, Universidade Federal da Paraíba, Campus II, CEP 58397-000, Areia (PB), Brasil. klertonxavier@hotmail.com

5 Engenheiro Agrônomo, Dr., Professor do Departamento de Produção Animal e Vegetal, Faculdade de Ciências Agrárias, Universidade Federal do Amazonas, Av. Gal. Rodrigo Octávio Jordão Ramos, 3000, Setor Sul, Coroado I, CEP 69077-000, Manaus (AM), Brasil. jfsilva@ufam.edu.br

Recebido para publicação em 7/05/2012 e aceito em 22/10/2013 
burning of the stump and application of 2,4-D + picloram in cut and girdled plants. The brushing lubricating oil on the basis of girdled plants also showed a promising strategy to control invasive.

Keywords: biological invasion; control plants; algaroba; caatinga biome.

\section{INTRODUÇÃO}

A invasão biológica por espécies vegetais representa atualmente uma ameaça ao patrimônio genético autóctone de todos os biomas do planeta. No semiárido brasileiro, diversas espécies exóticas têm se revelado invasoras de áreas antropizadas e se constituem um problema na região (ANDRADE et al., 2008; ANDRADE et al., 2009; FABRICANTE et al., 2009). Dentre essas espécies, Prosopis juliflora (Sw.) DC. (Fabaceae), conhecida como algaroba, planta nativa da América Central e norte da América do Sul, tem se revelado a mais agressiva no domínio de caatinga e ecossistemas associados. Embora não exista levantamento quantitativo preciso, estima-se que a área invadida pela referida invasora seja muito superior a um milhão de hectares (ANDRADE et al., 2008), concentrando-se principalmente em solos mais profundos e nos domínios de matas ciliares, onde a água é potencialmente mais abundante.

Apesar da gravidade que as invasões biológicas representam, poucas ações de controle têm sido empreendidas, visando reduzir os impactos provocados por essas espécies, dentre elas, Prosopis juliflora, cujas consequências vão desde a modificação de nichos à extinção local de espécies nativas, inclusive outras arbóreas, além da própria descaracterização dos ecossistemas ocupados. O desenvolvimento e a aplicação de técnicas de controle eficientes podem não somente conter o avanço da referida espécie invasora e reduzir os danos provocados sobre a biota nativa, mas podem também criar condições para que as espécies nativas possam se regenerar e se estabelecerem novamente nos nichos ocupados (WEBSTER et al., 2007).

Apesar de o controle mecânico ser o método mais utilizado pelos agricultores e pecuaristas, sua baixa eficiência é observada na maioria das vezes (CARMONA et al., 2001; RIBEIRO e ZAÚ, 2007; FABRICANTE et al., 2009). O anelamento do floema do tronco também é outra técnica muito utilizada, porém, seus efeitos variam amplamente conforme a espécie (STONE, 1974) e a idade das plantas (WILSON, 1998; WILSON e GARTNER, 2002; GOREN et al., 2004; CHOI et al., 2010). $\mathrm{O}$ anelamento pode reduzir o crescimento do tronco, dos ramos terminais e do sistema radicular, modificando a absorção de água e o transporte de nutrientes e hormônios (GOREN et al., 2004; CHOI et al., 2010). Outra prática de controle bastante utilizada é o fogo, especialmente devido ao seu baixo custo. Diversas espécies lenhosas apresentam alto grau de suberização em seus troncos e ramos, o que resultaria em um isolamento térmico dos tecidos internos da planta. Por outro lado, os indivíduos menores e menos lenhosos não possuem esta suberização, apresentando uma taxa de mortalidade mais elevada que os indivíduos maiores (HOFFMANN e SOLBRIG, 2003). Entretanto, o fogo é uma técnica com restrições de uso, uma vez que intensifica o processo de degradação do solo e pode afetar negativamente o meio ambiente (VITÓRIA FILHO, 1986).

A maior ênfase no controle de plantas invasoras tem sido dada ao uso de herbicidas, por causa da sua eficácia, praticidade e vantajosa relação custo/benefício (CARMONA et al., 2001; QASEM, 2007). Os herbicidas mais utilizados no manejo de plantas perenes têm sido o 2,4-D (VIEIRA et al., 1999; 2,4-D: FACT SHEET, 2000) e o picloram em solução aquosa. Ambos os componentes controlam ampla gama de espécies de folha larga, herbáceas, arbustivas e arbóreas, e são seletivos para gramíneas (RODRIGUES e ALMEIDA, 2005). Estes produtos podem ser aplicados via foliar ou nas cepas (tocos), após terem sido cortadas. Os óleos minerais por terem efeito herbicida de contato também são usados como alternativas para o controle de algumas espécies. Estes podem atuar diretamente no local atingido, provocando encharcamento das folhas, seguido de seu escurecimento e morte (DEUBER, 1992).

Apesar da carência de informações científicas acerca da eficiência e dos possíveis efeitos nocivos à saúde e ao meio ambiente, agricultores e pecuaristas vêm utilizando, de forma empírica, diversas técnicas e produtos para combater a invasora Prosopis juliflora. O objetivo deste estudo foi avaliar a eficiência de diferentes métodos no controle de populações de Prosopis juliflora em duas áreas invadidas na caatinga. 


\section{MATERIAL E MÉTODOS}

O estudo foi conduzido de dezembro de 2009 a dezembro de 2010, em duas populações de Prosopis juliflora no Estado da Paraíba, Brasil: População I, na Fazenda Boa Vista $\left(07^{\circ} 23^{\prime} 27^{\prime}\right.$ 'S, $36^{\circ} 31^{\prime} 58^{\prime \prime} \mathrm{W}$ e altitude média de $458 \mathrm{~m}$ ), localizada no município de São João do Cariri (Mesorregião do Cariri Oriental), cuja precipitação média anual é de 381,4 mm; e População II, no Assentamento Gruta Funda (06 51 '11,3”S, 35055'51,5”'W e altitude média de $407 \mathrm{~m}$ ), localizado no município de Algodão de Jandaíra (Mesorregião do Agreste Paraibano), cuja precipitação média anual é de 550 $\mathrm{mm}$. Estas propriedades foram selecionadas por apresentarem alto grau de invasão por Prosopis juliflora.

O delineamento utilizado foi inteiramente casualizado, em esquema fatorial triplo $(2 \times 2 \times 8)$, sendo duas populações de Prosopis juliflora distantes aproximadamente $200 \mathrm{~km}$ entre si; dois estádios de crescimento - regenerante e adulto e oito tratamentos, com 10 repetições. Neste trabalho foram considerados regenerantes aqueles indivíduos com diâmetro ao nível do solo (DNS) inferior a 5 $\mathrm{cm}$ e adultos, DNS igual ou superior a $5 \mathrm{~cm}$. Os tratamentos testados foram: testemunha; anelamento do floema do caule; anelamento e pincelamento de óleo lubrificante usado; anelamento e aplicação de 2,4-D + picloram (2,4-D, $240 \mathrm{~g} \mathrm{~L}^{-1}$ de ingrediente ativo; picloram $64 \mathrm{~g} \mathrm{~L}^{-1}$ de ingrediente ativo) a $5 \%$ do volume de calda; corte raso das plantas; corte raso e queima das cepas; corte raso e pincelamento de óleo lubrificante usado; corte raso e aplicação de 2,4-D + picloram. No total foram monitorados 320 indivíduos, dentre estes, 160 eram regenerantes e 160 adultos. $\mathrm{O}$ anelamento (retirada de uma cinta de 10 $\mathrm{cm}$ da casca e do floema, em toda volta do caule) e o corte raso (supressão da parte área) foram efetuados numa altura de 10 a $20 \mathrm{~cm}$ do colo da planta. O óleo lubrificante usado, sem diluição, foi pincelado sobre toda a superfície da casca nas cepas, assim como sobre a superfície anelada e a porção da casca abaixo desta. O herbicida foi aplicado imediatamente após o corte e ou anelamento, com o floema ainda ativo. Para isto, foi utilizado um pulverizador costal, com capacidade para $20 \mathrm{~L}$, provido de bicos com pontas de pulverização do tipo cone cheio de forma que a calda escorresse para os lados laterais da cepa e das porções aneladas. Para a queima da cepa utilizou-se a biomassa cortada da própria planta.

Na Tabela 1 estão discriminadas as médias biométricas e os desvios padrão dos indivíduos de Prosopis juliflora por ocasião da aplicação dos tratamentos. A altura foi estimada por meio de vara telescópica e os DNS e a espessura da casca, por meio de suta dendrométrica e paquímetro, respectivamente.

As variáveis avaliadas, a cada 30 dias, foram porcentagem de controle, número médio de brotos, por planta, abaixo do anel ou do corte e comprimento médio de brotações. Para a porcentagem de controle utilizaram-se os critérios de Frans e Talbert (1977) e Carmona et al. (2001), que consideram o nível de $100 \%$ como controle total; $90-99 \%$, controle eficiente; $80-89 \%$, controle aceitável; 50-79\%, controle não aceitável; e 0-49\%, controle insuficiente. No campo, a morte dos indivíduos foi constatada quando os tecidos do floema se apresentaram completamente secos, pela ausência de brotações e pela constatação de copa totalmente seca e desfolhada (plantas com parte aérea).

Os dados das repetições foram transformados em $\sqrt{ }(x+1)$, submetidos à análise de variância para obtenção do valor de $\mathrm{F}$ e as médias comparadas pelo teste de Tukey $(p \leq 0,05)$. A análise estatística foi realizada através do Software estatístico Genes

TABELA 1: Médias biométricas dos indivíduos de Prosopis juliflora por ocasião da aplicação dos tratamentos de controle.

TABLE 1: Individual biometric mean of Prosopis juliflora during the application of control treatments.

\begin{tabular}{ccccc}
\hline Populações & Estádios & Altura $(\mathrm{m})$ & DNS $(\mathrm{cm})$ & Espessura da casca $(\mathrm{mm})$ \\
\hline \multirow{2}{*}{ População I } & Regenerante & $2,7 \pm 0,78^{1}$ & $2,5 \pm 0,72$ & $1,0 \pm 0,27$ \\
& Adulto & $8,3 \pm 2,10$ & $14,0 \pm 5,76$ & $4,4 \pm 1,18$ \\
\multirow{2}{*}{ População II } & Regenerante & $2,8 \pm 0,87$ & $2,9 \pm 0,89$ & $1,1 \pm 0,29$ \\
& Adulto & $6,0 \pm 1,19$ & $10,3 \pm 4,00$ & $3,1 \pm 0,58$ \\
\hline
\end{tabular}

Em que: População I = indivíduos de Prosopis juliflora da Fazenda Boa Vista; População II = indivíduos do Assentamento Gruta Funda; DNS = diâmetro ao nível do solo; ${ }^{1}$ Desvio Padrão. 
(CRUZ, 2006).

\section{RESULTADOS E DISCUSSÃO}

$\mathrm{O}$ experimento demonstrou que, para as variáveis avaliadas, houve variação estatística $(p<0,05)$ no comportamento de Prosopis juliflora em relação aos tratamentos de controle, aos estádios de crescimento e às populações de plantas estudadas. Os tratamentos em que se aplicou herbicida e queima mostraram-se mais eficientes no combate à invasora. Contudo, é importante destacar, que, mesmo sendo menos eficiente, a utilização do óleo lubrificante usado controlou satisfatoriamente a invasora, particularmente no que diz respeito aos indivíduos adultos. As plantas adultas mostraramse mais suscetíveis que os regenerantes aos tratamentos, constatando-se a morte de $70 \%$ e 54\%, respectivamente. As populações de Prosopis juliflora também apresentaram diferença no seu comportamento em relação aos tratamentos de controle, o que pode ter ocorrido devido às variações edafoclimáticas das áreas de estudo (Tabela 2).

$\mathrm{O}$ anelamento isolado estimulou a rebrota de mais de $50 \%$ das plantas aneladas (Tabela 3 ), proporcionando um controle insuficiente, de acordo

TABELA 2: Resumo da análise de variância para as variáveis controle, número de brotações e altura das brotações de Prosopis juliflora.

TABLE 2: Variance analysis summary for variables control, number of shoots and height of shoots of Prosopis juliflora.

\begin{tabular}{lcccc}
\hline \multirow{2}{*}{ Fontes de variação } & \multirow{2}{*}{ GL } & \multicolumn{3}{c}{ Quadrados Médios das Variáveis } \\
\cline { 3 - 5 } & & Controle & $\mathrm{N}^{0}$ de brotos & Altura de brotos \\
\hline Tratamento (T) & 7 & $481,42^{* *}$ & $12,00^{* *}$ & $164,45^{* *}$ \\
Estádio (E) & 1 & $112,86^{* *}$ & $1,86^{* *}$ & $21,48^{* *}$ \\
População (P) & 1 & $92,39^{* *}$ & $5,72^{* *}$ & $12,21^{*}$ \\
E x P & 1 & $30,96^{*}$ & $3,32^{* *}$ & $60,40^{* *}$ \\
T x P & 7 & $26,87^{* *}$ & $1,73^{* *}$ & $11,63^{* *}$ \\
E x T & 7 & $25,11^{* *}$ & $0,47^{\text {ns }}$ & $9,97^{* *}$ \\
T x E x P & 7 & $71,91^{* *}$ & $3,37^{* *}$ & $50,22^{* *}$ \\
\hline Resíduo & 288 & 6,00 & 0,24 & 3,10 \\
\hline CV\% & - & 37,27 & 34,46 & 66,89 \\
\hline
\end{tabular}

Em que: $\mathrm{GL}=$ graus de liberdade; $* *(p<0,01) ; *(p<0,05) ;{ }^{\text {ns }}$ não significativo.

TABELA 3: Porcentagem de controle de Prosopis juliflora por tratamento.

TABLE 3: Percent control of Prosopis juliflora per treatment.

\begin{tabular}{lcccc}
\hline \multirow{2}{*}{ Tratamentos } & \multicolumn{2}{c}{ População I } & \multicolumn{2}{c}{ População II } \\
\cline { 2 - 5 } & Regenerante (\%) & Adulto (\%) & Regenerante (\%) & Adulto (\%) \\
\hline Testemunha & 0 & 0 & 0 & 0 \\
Anelamento & 0 & 50 & 50 & 30 \\
Anelamento e aplicação de óleo & 50 & 100 & 60 & 90 \\
Anelamento e aplicação de herbicida & 100 & 100 & 100 & 100 \\
Corte & 20 & 0 & 0 & 100 \\
Corte e queima da cepa & 100 & 100 & 100 & 100 \\
Corte e aplicação de óleo & 50 & 20 & 50 & 100 \\
Corte e aplicação de herbicida & 100 & 100 & 100 & 100
\end{tabular}

Em que: População I = indivíduos de Prosopis juliflora da Fazenda Boa Vista; População II = indivíduos do Assentamento Gruta Funda. 
com a classificação proposta por Frans e Talbert (1977). Apesar de reduzir o crescimento, provocar desfolha total e desidratação completa de ramos e tecidos acima do anel, a superfície abaixo do anelamento emitiu brotos e as plantas conseguiram crescer e se regenerar.

A inibição do crescimento de novos ramos está, geralmente, associada ao controle apical promovido pela produção de auxinas próximas às regiões meristemáticas (TAIZ e ZEIGER, 2004). Assim, quando o transporte de auxinas à base é interrompido, as gemas caulinares são liberadas do controle apical e retomam seu crescimento. Para Goren et al. (2004) e Choi et al. (2010), o anelamento também pode reduzir o crescimento de raízes e, concomitantemente, modificar a absorção e o transporte de nutrientes para a parte aérea de plantas.

A aplicação de óleo lubrificante usado aumentou significativamente a porcentagem de controle de Prosopis juliflora. Os tratamentos "anelamento e aplicação de óleo" e "corte e aplicação de óleo" apresentaram porcentagens de controle igual ou superior a $50 \%$ para os indivíduos regenerantes e adultos da População II. Aparentemente, o óleo apresentou efeito herbicida, principalmente em plantas adultas, nas quais foi observada maior mortalidade. Os danos observados foram: redução do crescimento em ramos, queda de folhas e morte de indivíduos a partir do terceiro mês após aplicação. Em estudos realizados com as espécies Acacia farnesiana Wall. e Mimosa pteridifolia Benth. o óleo lubrificante não causou nenhum dano às plantas (CARMONA et al., 2001), revelando-se ineficiente para o controle destas espécies. Para Lin e Mendelssohn (1996) o óleo lubrificante pode causar efeitos fitotóxicos físicos e químicos, cuja intensidade pode variar com o tipo e a quantidade, bem como com a espécie.

A aplicação de 2,4-D + picloram proporcionou $100 \%$ de controle de Prosopis juliflora aos 90 dias, sendo, portanto, uma técnica muito eficiente. A morte das plantas foi constatada após desfolha total e subsequente secagem de todos os tecidos floemáticos. Estudos realizados por Carmona et al. (2001) mostraram que a aplicação de 2,4-D + picloram na concentração de 4\% controlou totalmente Acacia farnesiana e Mimosa pteridifolia, quando o corte foi efetuado rente ao solo. No corte a $20 \mathrm{~cm}$ do solo, o herbicida apresentou controle total apenas em plantas de Mimosa pteridifolia menores que $1,5 \mathrm{~m}$. A eficiência do 2,4-D + picloram deve-se provavelmente ao seu mecanismo de ação e a sua toxicidade. Estes herbicidas, quando aplicados em plantas sensíveis, induzem mudanças metabólicas e bioquímicas, podendo levá-las a morte (SILVA et al., 2007). Acredita-se que esses produtos interfiram na ação da enzima RNA-polimerase e, consequentemente, na síntese de ácidos nucleicos e de proteínas, induzindo intensa proliferação celular de tecidos, além de causar interrupção do floema e impedir o movimento dos fotoassimilados das folhas para o sistema radicular. O 2,4-D é um herbicida altamente seletivo, sistêmico e pós-emergente. Uma vez absorvido, é translocado dentro da planta, acumulando-se nas regiões meristemáticas dos pontos de crescimento das raízes e agindo através do crescimento desordenado das células, impedindo o transporte de água e nutrientes através da planta (2,4-D: FACT SHEET, 2000). O picloram é um herbicida auxínico extremamente ativo em dicotiledôneas, além de ser fracamente adsorvido no solo. Apresenta longa persistência no ambiente, com meia-vida de 20 a 300 dias (THILL, 2003; SANTOS et al., 2006; SILVA et al., 2007).

$\mathrm{O}$ corte raso isolado também se mostrou um método ineficiente no combate à invasora, pois a maioria dos indivíduos rebrotou e sobreviveu. No entanto, verificou-se controle de $100 \%$ dos indivíduos adultos na População II (Tabela 3). O controle restrito das plantas adultas ocorreu devido, provavelmente, ao estresse sofrido pela execução do corte ou por fatores fisiológicos como baixo conteúdo de reserva de carboidratos acumulado nas raízes para o crescimento de brotos, visto que estas plantas se encontravam em fase de florescimento e frutificação. O corte raso também não foi eficiente no controle de Acacia farnesiana e Mimosa pteridofita, (CARMONA et al., 2001), nem no controle de Lonicera morrowii Gray na Pennsylvania, pois os indivíduos se regeneraram (LOVE e ANDERSON, 2009). De acordo com Dias (1993), o corte do sistema aéreo de muitos arbustos e árvores, de modo geral, não apresenta controle satisfatório, pois, ao ser cortado o tronco volta a rebrotar em pouco tempo, não sendo possível um controle em longo prazo. Para Love e Anderson (2009) as plantas estão mais susceptíveis ao corte quando os níveis de carboidratos nas raízes são mínimos, ou seja, logo após a formação de folhas, flores e frutos.

A queima das cepas imediatamente após o corte revelou-se um método muito eficiente, pois controlou $100 \%$ dos indivíduos de 
Prosopis juliflora. Esse resultado deveu-se provavelmente à falta de adaptação desta espécie ao calor excessivo e a pouca espessura de sua casca (Tabela 1). Para Heringer e Jacques (2001), a resistência de plantas arbóreas ao fogo está relacionada à espessura e ao tipo de casca, assim como à integridade do tecido cambial do caule e da raiz. Temperaturas elevadas implicam na desidratação dos tecidos meristemáticos, responsáveis pela divisão celular e pela produção de novas células necessárias ao crescimento vegetal. A queima de árvores em um período de alta atividade fisiológica reduz a biomassa das raízes e as taxas de crescimento, e aumenta a mortalidade em relação às árvores não queimadas (BUSSE et al., 2000).

Em ambas as populações, os melhores resultados foram obtidos quando houve integração dos métodos de controle. Com relação à comparação entre médias, o teste de Tukey revelou diferença estatística significativa entre os tratamentos. Em plantas aneladas, o melhor controle para os regenerantes foi conseguido com aplicação de 2,4-D + picloram, já para os adultos a aplicação do herbicida e o pincelamento de óleo lubrificante usado obtiveram maior controle quando comparados com o anelamento isolado. A aplicação de óleo, embora tenha apresentado menor eficácia em relação à aplicação de 2,4-D + picloram, pode servir como uma alternativa econômica para o controle de Prosopis juliflora por ser um produto de baixo custo e de fácil obtenção. Porém, a aplicação deste produto parece não ser tão eficiente nos indivíduos regenerantes, sendo, portanto, recomendado apenas para os adultos (Tabela 4).

Nas condições em que este estudo foi realizado, as elevadas taxas de controle em plantas adultas devem-se, provavelmente, a fatores fisiológicos como baixo conteúdo de reserva de carboidratos acumulado para o crescimento de brotos, haja vista seu esgotamento em consequência das fenofases de florescimento e frutificação em que estas plantas se encontravam. Durante essas fases são demandadas, pela planta, grande quantidade de reservas para produção de flores e frutos, afetando o crescimento das brotações. Em relação aos tratamentos que foram submetidos ao corte, os melhores resultados foram alcançados com esse associado à queima da cepa e à aplicação de 2,4-D + picloram na cepa, uma vez que controlaram $100 \%$ dos indivíduos nos estratos regenerante e adulto das duas populações estudadas. Nos tratamentos envolvendo corte, seja de forma isolada ou associada a outros métodos, os indivíduos adultos foram controlados totalmente em $75 \%$ dos tratamentos, já os regenerantes obtiveram controle total em 50\% dos casos, de modo que os adultos se mostram mais susceptíveis a esses tratamentos.

Em algumas plantas, brotações começaram a emergir 10 dias após aplicação dos tratamentos, sendo constatado aumento a cada período de avaliação. O número de brotos foi influenciado estatisticamente pelo tratamento. A maior emergência de brotações foi observada em plantas submetidas ao corte raso, porém, nos regenerantes da População I, não diferiu estatisticamente do

TABELA 4: Médias dos tratamentos no controle de Prosopis juliflora nas duas populações de estudo.

TABLE 4: Treatment means for control of Prosopis juliflora in the two study populations.

\begin{tabular}{ccccc}
\hline \multirow{2}{*}{ Tratamentos } & \multicolumn{2}{c}{ População I } & \multicolumn{2}{c}{ População II } \\
\cline { 2 - 5 } & Regenerante & Adulto & Regenerante & Adulto \\
\hline Testemunha & $01,00 \mathrm{dA}$ & $01,00 \mathrm{dA}$ & $01,00 \mathrm{cA}$ & $01,00 \mathrm{cA}$ \\
Anelamento & $01,00 \mathrm{~dB}$ & $07,14 \mathrm{bA}$ & $07,14 \mathrm{bA}$ & $05,53 \mathrm{bB}$ \\
Anelamento e aplicação de óleo & $07,14 \mathrm{bB}$ & $10,05 \mathrm{aA}$ & $07,81 \mathrm{bB}$ & $09,53 \mathrm{aA}$ \\
Anelamento e aplicação de herbicida & $10,05 \mathrm{aA}$ & $10,05 \mathrm{aA}$ & $10,05 \mathrm{aA}$ & $10,05 \mathrm{aA}$ \\
Corte & $04,58 \mathrm{cA}$ & $01,00 \mathrm{~dB}$ & $01,00 \mathrm{cB}$ & $10,05 \mathrm{aA}$ \\
Corte e queima da cepa & $10,05 \mathrm{aA}$ & $10,05 \mathrm{aA}$ & $10,05 \mathrm{aA}$ & $10,05 \mathrm{aA}$ \\
Corte e aplicação de óleo & $07,14 \mathrm{bA}$ & $04,58 \mathrm{cB}$ & $07,14 \mathrm{bB}$ & $10,05 \mathrm{aA}$ \\
Corte e aplicação de herbicida & $10,05 \mathrm{aA}$ & $10,05 \mathrm{aA}$ & $10,05 \mathrm{aA}$ & $10,05 \mathrm{aA}$ \\
\hline
\end{tabular}

Em que: letras maiúsculas nas linhas comparam estádios de crescimento e minúsculas nas colunas comparam tratamentos. Dados transformados em $\sqrt{ }(x+1) ; C V=37,27 \%$; diferença mínima significativa $(\mathrm{DMS})=1,52$. 
anelamento e nos adultos da População II, não diferiu estaticamente de nenhum outro tratamento aplicado (Tabela 5).

A grande quantidade de brotos em plantas regenerantes cortadas e aneladas deve-se ao fato destes indivíduos possuírem mais gemas meristemáticas que adultos. Exceto nas plantas adultas da População II, o óleo lubrificante usado contribuiu significativamente para a redução do número de brotações nas plantas, fato ocorrido devido ao menor número de indivíduos que resistiram aos respectivos tratamentos. Nesses indivíduos, a rebrota teve início poucos dias após, gerando brotações pouco numerosas e de vigor relativamente baixo.

$\mathrm{O}$ anelamento e o corte isolados induziram, na maioria dos casos, o rápido crescimento de brotações (exceto indivíduos adultos da População II), diferenciando-se dos demais tratamentos. Segundo Taiz e Zeiger (2004), o crescimento de brotações laterais é controlado por níveis de auxinas presentes no caule e pelo transporte desses compostos dos meristemas à base. Então, quando o transporte é interrompido o nível de auxina no caule fica abaixo do ótimo, implicando no crescimento de uma ou várias gemas laterais. A altura das brotações variou, estatisticamente, tanto entre os estádios de crescimento quanto entre os tratamentos aplicados. (Tabela 6).

Em alguns casos os indivíduos regenerantes produziram brotações significativamente menores que os adultos, o que pode ser explicado pelo maior número de gemas meristemáticas em crescimento de indivíduos recrutados e, consequentemente,

TABELA 5: Médias do número de brotações de Prosopis juliflora nas duas populações de estudo.

TABLE 5: Mean number of shoots of Prosopis juliflora in the two study populations.

\begin{tabular}{lcccc}
\hline \multirow{2}{*}{ Tratamentos } & \multicolumn{2}{c}{ População I } & \multicolumn{2}{c}{ População II } \\
\cline { 2 - 5 } & Regenerante & Adulto & Regenerante & Adulto \\
\hline Anelamento & $2,55 \mathrm{aA}$ & $1,87 \mathrm{bB}$ & $1,92 \mathrm{cA}$ & $1,30 \mathrm{aB}$ \\
Anelamento e aplicação de óleo & $1,70 \mathrm{bA}$ & $1,51 \mathrm{cA}$ & $1,00 \mathrm{dA}$ & $1,22 \mathrm{aA}$ \\
Anelamento e aplicação de herbicida & $1,00 \mathrm{cA}$ & $1,00 \mathrm{dA}$ & $1,00 \mathrm{dA}$ & $1,00 \mathrm{aA}$ \\
Corte & $2,66 \mathrm{aA}$ & $2,82 \mathrm{aA}$ & $3,39 \mathrm{aA}$ & $1,00 \mathrm{aB}$ \\
Corte e queima da cepa & $1,00 \mathrm{cA}$ & $1,00 \mathrm{dA}$ & $1,00 \mathrm{dA}$ & $1,00 \mathrm{aA}$ \\
Corte e aplicação de óleo & $2,05 \mathrm{bA}$ & $2,00 \mathrm{bA}$ & $2,68 \mathrm{bA}$ & $1,00 \mathrm{aB}$ \\
Corte e aplicação de herbicida & $1,00 \mathrm{cA}$ & $1,00 \mathrm{dA}$ & $1,00 \mathrm{dA}$ & $1,00 \mathrm{aA}$ \\
\hline
\end{tabular}

Em que: letras maiúsculas nas linhas comparam estádios de crescimento e minúsculas nas colunas comparam tratamentos. Dados transformados em $\sqrt{ }(x+1) ; C V=34,4 \%$; diferença mínima significativa (DMS) $=0,35$.

TABELA 6: Altura média de brotações de Prosopis juliflora nas duas populações de estudo.

TABLE 6: Mean height of shoots of Prosopis juliflora in the two study populations.

\begin{tabular}{|c|c|c|c|c|}
\hline \multirow{2}{*}{ Tratamentos } & \multicolumn{2}{|c|}{ População I } & \multicolumn{2}{|c|}{ População II } \\
\hline & Regenerante & Adulto & Regenerante & Adulto \\
\hline Anelamento & $5,33 \mathrm{aA}$ & $5,65 \mathrm{bA}$ & $5,40 \mathrm{aB}$ & $7,14 \mathrm{aA}$ \\
\hline Anelamento e aplicação de óleo & $3,60 \mathrm{bA}$ & $1,00 \mathrm{cB}$ & $4,03 \mathrm{bA}$ & $2,77 \mathrm{bB}$ \\
\hline Anelamento e aplicação de herbicida & $1,00 \mathrm{cA}$ & $1,00 \mathrm{cA}$ & $1,00 \mathrm{cA}$ & $1,00 \mathrm{cA}$ \\
\hline Corte & $5,76 \mathrm{aB}$ & $8,56 \mathrm{aA}$ & $6,22 \mathrm{aA}$ & $1,00 \mathrm{cB}$ \\
\hline Corte e queima da cepa & $1,00 \mathrm{cA}$ & $1,00 \mathrm{cA}$ & $1,00 \mathrm{cA}$ & $1,00 \mathrm{cA}$ \\
\hline Corte e aplicação de óleo & $4,58 \mathrm{aB}$ & $6,67 \mathrm{bA}$ & $5,74 \mathrm{aA}$ & $1,00 \mathrm{cB}$ \\
\hline Corte e aplicação de herbicida & $1,00 \mathrm{cA}$ & $1,00 \mathrm{cA}$ & $1,00 \mathrm{cA}$ & $1,00 \mathrm{cA}$ \\
\hline
\end{tabular}

Em que: letras maiúsculas nas linhas comparam estádios de crescimento e minúsculas nas colunas comparam tratamentos. Dados transformados em $\sqrt{ }(\mathrm{x}+1) ; \mathrm{CV}=66,9 \%$; diferença mínima significativa $(\mathrm{DMS})=1,2$. 
pelo aumento da competição por reservas entre as brotações. Em plantas adultas, principalmente, ocorreu variação de comportamento entre populações para um mesmo tratamento. Esta variação pode estar relacionada às diferenças na disponibilidade de água do solo e ao regime de chuva de cada região, fertilidade do solo, luz, entre outros fatores.

Todas as variáveis utilizadas foram úteis para avaliar a eficácia dos tratamentos de controle. Os resultados sugerem que a aplicação de óleo lubrificante usado, embora menos eficiente que o herbicida e o fogo, pode constituir uma alternativa economicamenteviável para ocontroledepopulações invasoras de Prosopis juliflora, notadamente para os indivíduos adultos, pois quando utilizado associado ao anelamento e ao corte controlou $95 \%$ e $60 \%$ das plantas tratadas, respectivamente. A viabilização do uso do óleo lubrificante usado como herbicida reside na facilidade de sua obtenção em praticamente todas as regiões e em qualquer época do ano. Dessa forma, diminui os riscos de perda da época mais favorável para a aplicação do controle, além de constituir um produto de baixo custo.

\section{CONCLUSÕES}

Os resultados obtidos neste estudo permitiram chegar às seguintes conclusões:

A aplicação de 2,4-D + picloram e a queima das cepas mostraram-se eficientes no controle de Prosopis juliflora;

O óleo lubrificante usado pode constituir uma alternativa viável economicamente para o controle dessa espécie;

As condições edafoclimáticas influenciaram a eficiência dos tratamentos;

São necessários estudos que avaliem a eficiência dos referidos métodos de controle, em diferentes épocas do ano, a fim de determinar o período em que as plantas de Prosopis juliflora estejam mais vulneráveis.

\section{AGRADECIMENTOS}

À Fundação O Boticário de Proteção à Natureza, pelo apoio financeiro concedido à realização desta pesquisa; à Universidade Federal da Paraíba e à equipe do Laboratório de Ecologia Vegetal (LEV), pelo apoio na condução da pesquisa.

\section{REFERÊNCIAS BIBLIOGRÁFICAS}

2,4-D: Fact sheet. Disponível em: $<$ http://www. gn.apc.orglpesticidestrustlaifacts/24d.htm $>$. Acesso em: 20 abr. 2012.

ANDRADE, L. A. et al. Invasão biológica por Prosopis juliflora (Sw.) DC.: impactos sobre a diversidade e a estrutura do componente arbustivoarbóreo da caatinga no estado do Rio Grande do Norte, Brasil. Acta Botânica Brasílica, São Paulo, v. 23, p. 935-943, 2009.

ANDRADE, L. A. et al. Algaroba (Prosopis juliflora (Sw.) DC.): Impactos sobre a fitodiversidade e estratégias de colonização em área invadida na Paraíba. Natureza \& Conservação, Goiás, v. 6, n. 2, p. 61-67, 2008.

BUSSE, M. D. et al. Tree growth and understory responses to low-severity prescribed burning in thinned Pinus ponderosa forests of central Oregon. Forest Science, Czech Republic, v. 46, p. 258-268, 2000.

CARMONA, R. et al. Controle de Acacia farnesiana e de Mimosa pteridofolia em pastagem. Pesquisa Agropecuária Brasileira, Brasília, v. 36, n. 10, p. 1301-1307, 2001.

CHOI, S. T. et al. Effect of different girdling dates on tree growth, fruit characteristics and reserve accumulation in a late-maturing persimmon. Scientia Horticulturae, Holanda, v. 126, p. 152155, 2010.

CRUZ, C. D. Programa Genes: Estatística Experimental e Matrizes. Viçosa: UFV, 2006. 285 p. DEUBER, R. Ciência das plantas infestantes: fundamentos. v. 1, Jaboticabal: Funep, 1992.

DIAS, F. N. B. Invasoras em pastagens. São Carlos: Embrapa-CPPSE, 1993. 13 p. (Circular Técnica, 4).

FABRICANTE, J. R. et al. Respostas da Parkinsonia aculeata $\mathrm{L}$. ao corte e queima em área invadida no agreste paraibano. Revista Brasileira de Ciências Agrárias, Pernambuco, v. 4, n. 3, p. 293-297, 2009. FRANS, R. E.; TALBERT, R. Measuring plant responses. In: TRUELOVE, B. (Ed.). Research methods in weed science. 2nd ed. New York: Southern Weed Science Society, 1977. 225 p.

GOREN, R. et al. Girdling: physiological and horticultural aspects. Horticultural Reviews, v. 30, p. 1-36, 2004.

HERINGER, I.; JACQUES, A. V. A. Adaptação das plantas ao fogo: enfoque na transição floresta campo. Ciência Rural, Santa Maria, v. 31, n. 6, p. 1085-1090, 2001. 
HOFFMANN, W. A.; SOLBRIG, O. T. The role of topkill in the differential response of savanna woody species to fire. Forest Ecology and Management, v. 180, p. 273-286, 2003.

LIN, Q.; MENDELSSOHN, I. A. A comparative investigation of the effects of Louisiana crude oil on the vegetation of fresh, brackish, and salt marsh. Marine Pollut Bull, EUA, v. 32, p. 202-209, 1996. LOVE, J. P.; ANDERSON, J. T. Seasonal Effects of Four Control Methods on the Invasive Morrow's Honeysuckle (Lonicera morrowii) and Initial Responses of Understory Plants in a Southwestern Pennsylvania Old Field. Restoration Ecology, v. 17, n. 4, p. 549-559, 2009.

QASEM, J. R. Chemical control of Prosopis farcta (Banks and Sol.) Macbride in the Jordan Valley. Crop Protection, USA, v. 26, p. 572-575, 2007. RIBEIRO, M. O.; ZAÚ, A. S. Levantamento populacional e manejo da exótica invasora Dracaena fragrans (L.) Ker-Gawl (Angiospermae - Liliaceae), em um trecho de Floresta Atlântica sob efeitos de borda no Parque Nacional da Tijuca, Rio de Janeiro, RJ. Revista Brasileira de Biociências, v. 5, n. 1, p. 21-23, 2007.

RODRIGUES, B. N.; ALMEIDA, F. S. Guia de herbicidas. 5. ed. Londrina: Ed. dos Autores, 2005. $592 \mathrm{p}$.

SANTOS, M. V. et al. Eficácia e persistência no solo de herbicidas utilizados em pastagem. Planta Daninha, v. 24, p. 391-398, 2006.

SILVA, A. A. et al. Herbicidas: classificação e mecanismo de ação. In: SILVA, A. A.; SILVA, J. F. (Eds.) Tópicos em manejo de plantas daninhas. Viçosa: Universidade Federal de Viçosa, 2007. p. 83-148.

STONE, E. L. The communal root system of red pine: growth of girdled trees. Forest Science, Czech Republic, v. 20, p. 294-305, 1974.

TAIZ, L.; ZEIGER, E. Fisiologia vegetal. 3. ed. Porto Alegre: Artmed, 2004. 719 p.

THILL, D. Growth regulator herbicides. In: Herbicide action course. West Lafayette: Purdue University, 2003. p. 267-291.

VIEIRA, E. M. et al. Estudo da adsorção/ dessorção do ácido 2,4-Diclorofenoxiacético (2,4D) em solo na ausência e presença de matéria orgânica. Química Nova, São Paulo, v. 22, n. 3, p. 305-308, 1999.

VITÓRIA FILHO, R. Controle de plantas daninhas em pastagens. In: FARIA, A. M. P. de (Ed.). Pastagens na Amazônia. Piracicaba: ESALQ, 1986. p. 71-90.

WEBSTER, C. R. et al. Invasion biology and control of invasive woody plants in eastern forests. Native Plants Journal, EUA, v. 8, n. 2, p. 97-106, 2007. WILSON ,B.; GARTNER. B. L. Effects of phloem girdling in conifers on apical control of branches, growth allocation and air in wood. Tree Physiology, v. 22, p. 347-353, 2002.

WILSON, B. F. Branches versus stems in woody plants: control of branch diameter growth and angle. Canadá. Journal of Botany, v. 76, p. 1852-1856, 1998. 